RESEARCH REPORT

\title{
Epidemiology of hypertension and associated cardiovascular risk factors in a country in transition: a population based survey in Tirana City, Albania
}

\author{
L Shapo, J Pomerleau, M McKee
}

J Epidemiol Community Health 2003;57:734-739

See end of article for authors' affiliations

Correspondence to: Dr L Shapo, London School of Hygiene and Tropical Medicine, Keppel Street, London WCIE 7HT, UK; Laidon.Shapo@|shtm.ac.uk

Accepted for publication 9 March 2003

\begin{abstract}
Study objective: To describe the prevalence of hypertension and other cardiovascular risk factors on the adult population of Tirana City (Albania).

Design: Cross sectional survey.

Setting: Tirana City in mid-2001.

Participants: 1120 adults aged 25 years and over (response rate=72.7\%).

Main results: Overall, hypertension prevalence (blood pressure $=140$ and/or $90 \mathrm{~mm} \mathrm{Hg}$, or known hypertensive receiving anti-hypertensive treatment) was $31.8 \%(36.6 \%$ and $27.4 \%$ in men and women respectively). Age standardised prevalence of hypertension (adjusted to the adult population of Tirana) was $30.2 \%$ (99\% confidence intervals $29.8 \%$ to $30.6 \%)$ in men and $22.7 \%(22.3 \%$ to $23.1 \%)$ in women. Men were significantly more likely to be hypertensive than women ( $p$ value $=0.001$ ). Of those who had been diagnosed with hypertension, $87 \%$ were receiving anti-hypertensive therapy and more than half of them (52\%) were adequately controlled. The prevalence of hypertension increased with increasing age and was more common in the obese in both sexes. While the prevalence of hypertension matched that in other industrialised and transition countries, the combination of hypertension with other cardiovascular risk factors was rather less common.

Conclusion: These findings provide important new evidence on the prevalence of hypertension and its association with other cardiovascular risk factors in Albania. Albania is in a state of rapid transition, with evidence that risk factors for non-communicable diseases have already increased considerably over the past two decades. These finding provide a unique baseline against which future change can be compared.
\end{abstract}

t is well known that hypertension, smoking, obesity, increased blood lipids, unhealthy diet, and physical inactivity are primary risk factors for cardiovascular diseases (CVD). ${ }^{1-4}$ This has recently been confirmed by the Global Burden of Disease (GBD) Study update for 2000, which estimated that hypertension causes $50 \%$ of CVD worldwide, high blood cholesterol about one third, and inactive lifestyles, tobacco use and low fruit and vegetable intake about $20 \%$ each (percentages sum to $>100 \%$ as some risks overlap). ${ }^{5}$

In Albania, unlike other former communist countries of eastern Europe, mortality from CVD has traditionally been low, similar to other Mediterranean countries. ${ }^{6}$ During the communist regime, before the dramatic political changes in 1991, lifestyle was quite unique in Europe. ${ }^{7}$ Levels of exercise were high as agriculture was unmechanised and labour intensive. The few cars were reserved for senior officials. Diet was traditional, based on local produce. ${ }^{8}$ In the 1990s, however, the country opened rapidly to western influences, car ownership increased, and western foods became widely available, especially in cities. Consequently dietary patterns have changed and, for many, levels of exercise have fallen. ${ }^{9}$ It is not clear how these changes will influence cardiovascular diseases. Firstly, epidemiological data are extremely scarce. We have been unable to find any information on the prevalence of CVD risk factors (except diabetes) in Albania before or during the transition period. Secondly, mortality data from the 1990s cannot easily be interpreted because of uncertainty caused by large scale, but unquantified migration. Consequently this cross sectional survey of health and lifestyle provides a baseline against which future changes can be compared.
This paper reports the prevalence of hypertension and its association with other CVD risk factors in the adult population of Tirana, capital of Albania, in 2001.

\section{METHODS}

A population based survey was undertaken in 2001 to investigate health behaviours and health status of people aged 25 years and over living in Tirana City. Ethical approval was granted by the Albanian Ministry of Health and the London School of Hygiene and Tropical Medicine.

The least common major condition examined was type 2 diabetes (results will be reported elsewhere ${ }^{10}$ ). This determined the required sample size, estimated to be 1188 people to be able to detect a prevalence of $2.9 \%$, taking $3.7 \%$ as the worst value. To allow for non-response, over-sampling of about $25 \%$ was undertaken. Given uncertainties about the precise resident population at the time of study, a two stage cluster sampling technique ${ }^{11}$ was used based on the published list of households for the 1997 general elections (UNDP unpublished data). Tirana is divided into 256 zones (map division). Based on this division 58 zones were randomly selected with probability proportional to size. From each zones, 12 households were chosen at random. This yielded 696 households, which was expected to yield at least 1392 adults (assuming an average of two adults aged 25 years and over per household). Of the 1540 people contacted 1120 (535 men and 585 women) agreed to participate (response rate $72.7 \%$ ). The final sample tended to be slightly older than the reference population. For this reason, the results presented in this paper are stratified by age group and the overall prevalence rates are age standardised. There were no women known to be pregnant in the study. 
All respondents were invited to attend a health centre in Tirana. Interviews were conducted, in three parts: (a) standard questions on demographic and socioeconomic information (sex, age, family status, educational level, family income) and health behaviours (physical activity at work and during leisure time, smoking, alcohol intake, and diet); (b) anthropometric (height, weight, waist, hip circumferences) and blood pressure measurements; and (c) blood samples and a glucose tolerance test.

Questionnaire design drew on earlier surveys conducted in other transition countries. ${ }^{13}$ The questionnaire was translated from English into Albanian by the principal investigator and back translated by another Albanian physician and compared before being distributed. Smoking status was divided into three categories: (a) never smokers; (b) former smokers; and (c) current smokers defined as people smoking at least one cigarette each day.

Anthropometric measurements used standardised procedures. ${ }^{14}$ Height was measured without shoes with subjects standing fully erect on a flat surface, with heels, buttocks and shoulders flat to the wall, and the subject looking straight ahead. Measurement was to the nearest centimetre. Weight was to the nearest $0.1 \mathrm{~kg}$ using digital scales. Subjects wore light clothing with no shoes. Waist circumference was measured to the nearest centimetre, halfway between the lower border of the ribs and the iliac crest, with the tape horizontal. Hip circumference was measured to the nearest centimetre at the maximum circumference, at the level of the greater trochanter. Body mass index (BMI) was calculated as weight (in kg) divided by height (in metres squared). Participants were categorised according to relative body weight status using WHO criteria ${ }^{15}$ (underweight: $\mathrm{BMI}<18.5 \mathrm{~kg} / \mathrm{m}^{2}$; normal: BMI 18.5-24.9; overweight: BMI 25.0-29.9; obese $\mathrm{BMI} \geqslant 30.0)$. Participants were considered centrally obese ${ }^{16}$ if waist-hip ratio $(\mathrm{W} / \mathrm{HR})$ was 0.95 or over for men and 0.85 or over for women.

Blood pressure (BP) was measured twice using an automatic sphygmomanometer, with participants seated after a five minute rest. ${ }^{17}$ Hypertension was defined as systolic blood pressure $\geqslant 140 \mathrm{~mm} \mathrm{Hg}$ and/or diastolic $\geqslant 90 \mathrm{~mm} \mathrm{Hg}$ or current use of anti-hypertensive drugs. ${ }^{18}$ Participants were categorised into four groups based on hypertension status: (a) normotensive; (b) newly diagnosed hypertensive; (c) known untreated hypertensive; and (d) known treated hypertensive.

Glucose tolerance and presence of diabetes were defined using 1999 WHO recommendations. ${ }^{19}$ Impaired glucose tolerance (IGT) was defined as fasting glucose of $<7.8 \mathrm{mmol} / \mathrm{l}$ and two hour post-load plasma glucose concentration between 7.8 and $11.0 \mathrm{mmol} / \mathrm{l}$. Diabetes was defined as two hour post-load plasma glucose concentration $\geqslant 11.1 \mathrm{mmol} / \mathrm{l}$ or on treatment for diabetes. Participants with a verified history of diabetes were classified as known diabetics (that is, taking insulin or oral hypoglycaemic agent or diet).$^{20}$

The fasting blood sample was also analysed for total cholesterol, high density lipoprotein (HDL) cholesterol, low density lipoprotein (LDL) cholesterol, and triglycerides.

Statistical analysis was undertaken using SPSS version 10.0. As age and sex are strong determinants of hypertension, descriptive results were presented for men and women separately and stratified by age group. In addition, as younger age groups tended to be under-represented in the study sample, age standardised prevalence rates (for the adult population of Tirana City) were calculated for men and women separately by applying age sex specific rates to the standard population of Tirana City (as it was in 1998).

Because the distributions of plasma triglycerides, plasma HDL, and LDL-cholesterol were skewed, log normal values were used; geometric means are presented in the results. The scale and potential impact of clustering of risk factors were examined in three ways. Firstly, age standardised prevalence of having hypertension plus any combination of other risk factors was calculated. Secondly, the likelihood of being hypertensive according to various risk factors was estimated using multiple logistic regression analysis. Because it was not possible to estimate the variance inflation due to within family clustering, ${ }^{21}$ it was decided to use a conservative statistical significance level of $p=0.01$ to reduce the risk of type I error. Thirdly, as a relatively simple way to place Albania in a comparative perspective in terms of overall burden of risk, people meeting the criteria for the metabolic syndrome (syndrome X), which increases the risk of cardiovascular disease, $^{22}$ and for which comparative American data are available, ${ }^{23}$ were identified. The syndrome is defined as the presence of three of: waist circumference greater than $102 \mathrm{~cm}$ in men and $88 \mathrm{~cm}$ in women; serum triglycerides level of at least $1.69 \mathrm{mmol} / \mathrm{l}$; HDL cholesterol level of less than 1.04 $\mathrm{mmol} / \mathrm{l}$ in men and $1.29 \mathrm{mmol} / \mathrm{l}$ in women; blood pressure of at least 130/85 mm Hg; or serum glucose level of at least 6.1 $\mathrm{mmol} / \mathrm{l}$.

\section{RESULTS}

Table 1 shows the distribution of participants according to blood pressure categories. Overall, almost one in three respondents was hypertensive; $12.9 \% \quad$ (99\% confidence

\begin{tabular}{|c|c|c|c|c|c|c|}
\hline Gender/age $(y)$ & $\mathrm{n}$ & Normotensive \% & $\begin{array}{l}\text { Newly* diagnosed } \\
\text { hypertensive \% }\end{array}$ & $\begin{array}{l}\text { Known untreated } \\
\text { hypertensive \% }\end{array}$ & $\begin{array}{l}\text { Known treated } \\
\text { hypertensive \% }\end{array}$ & Total hypertensive $\%$ \\
\hline Men (all ages) & 535 & 63.4 & 17.0 & 3.7 & 15.9 & 36.6 \\
\hline $25-34$ & 46 & 82.6 & 15.2 & 2.2 & 0 & 17.4 \\
\hline $35-44$ & 90 & 81.1 & 11.1 & 3.3 & 4.4 & 18.9 \\
\hline $45-54$ & 132 & 63.6 & 21.2 & 3.8 & 11.4 & 35.6 \\
\hline $55-64$ & 132 & 53.0 & 21.2 & 3.8 & 22.0 & 46.2 \\
\hline $65+$ & 135 & 54.8 & 13.3 & 4.4 & 27.4 & 45.2 \\
\hline $\mathrm{SBP}(\mathrm{mm} \mathrm{Hg}) \dagger$ & 535 & $125.7(8.5) \S$ & $147.6(10.3)$ & $150.7(16.6)$ & $152.8(14.2)$ & 150.1 (13.0)§ \\
\hline $\mathrm{DBP}(\mathrm{mm} \mathrm{Hg}) \ddagger$ & 535 & $75.9(6.6) \S$ & $88.1(9.2)$ & $91.2(8.8)$ & $88.7(9.9)$ & $88.7(9.4) \S$ \\
\hline Women (all ages) & 585 & 72.6 & 9.6 & 1.9 & 15.9 & 27.4 \\
\hline $25-34$ & 50 & 96.0 & 4.0 & 0 & 0 & 4.0 \\
\hline $35-44$ & 115 & 79.1 & 9.6 & 2.6 & 8.7 & 20.9 \\
\hline $45-54$ & 157 & 77.7 & 11.5 & 2.5 & 8.3 & 22.3 \\
\hline $55-64$ & 169 & 66.3 & 9.5 & 1.8 & 22.5 & 33.7 \\
\hline $65+$ & 94 & 55.3 & 9.6 & 1.1 & 34.0 & 44.7 \\
\hline SBP $(\mathrm{mm} \mathrm{Hg}) \dagger$ & 585 & $123.3(9.3) \S$ & $144.1(14.6)$ & $159.1(20.1)$ & $154.8(16.5)$ & $151.4(16.9) \S$ \\
\hline $\mathrm{DBP}(\mathrm{mm} \mathrm{Hg}) \ddagger$ & 585 & $75.5(6.8) \S$ & $85.2(7.4)$ & $87.3(7.3)$ & $85.2(8.6)$ & $85.6(8.1) \S$ \\
\hline
\end{tabular}




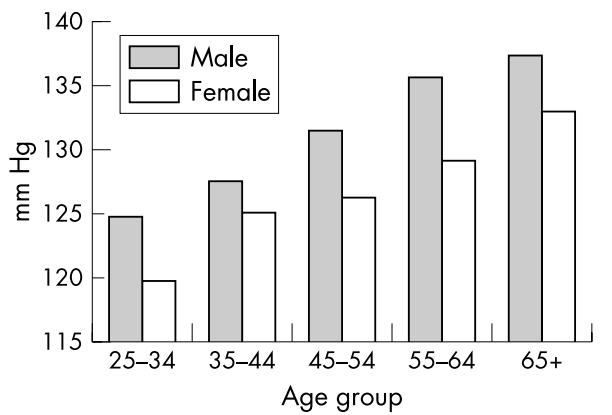

Figure 1 Mean systolic blood pressure* by sex an age group. *Known hypertensives and people receiving treatment were excluded $(n=178)$.

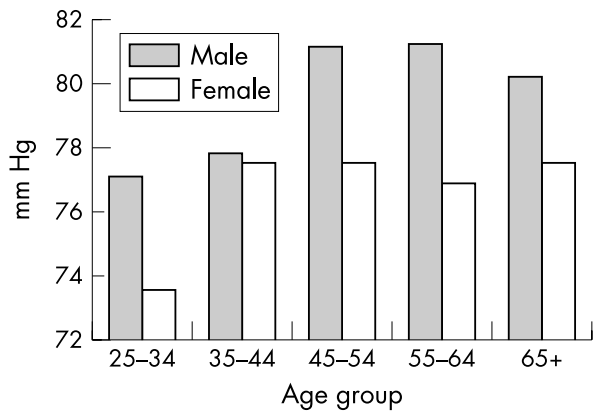

Figure 2 Mean diastolic blood pressure* by sex and age group. *Known hypertensives and people receiving treatment were excluded $(n=178)$.

intervals (CI): $12.1 \%$ to $13.7 \%$ ) of the respondents were newly diagnosed with hypertension; $2.8 \%$ (99\% CI: $1.1 \%$ to $4.5 \%$ ) were known but untreated hypertensive, and 15.9\% (99\% CI: $15.2 \%$ tol6.6\%) were known treated hypertensive. After standardising for age, the overall prevalence of hypertension age $25+$ was $30.2 \%$ in men $(99 \% \mathrm{CI}=29.8 \%$ to $0.6 \%)$ and $22.7 \%$ in women $(22.3 \%$ to $23.1 \%)$. Men were significantly more likely to be hypertensive than women (age adjusted odds ratio $(\mathrm{OR})=1.43,99 \% \mathrm{CI}: 1.02 \%$ to 2.02 ).

The overall prevalence of hypertension increased with age in both sexes ( $p$ value for trend $=0.001$ in men and $<0.0001$ in women), peaking at age 55-64 in men and at age 65 and over in women. SBP also increased with age in both men and women (fig 1) while the mean levels of DBP decreased in men after the age of 45-54 and stayed constant in women after the age of 35-44 (fig 2). About half of the respondents reported a family history of hypertension, especially among participants suffering from hypertension $(60.8 \% v 47.7 \%)$ ( $p$ value $<0.0001)$.

Of respondents who knew they were hypertensive, 87\% (369 of 425) were receiving anti-hypertensive therapy, with over half (191 of 369) adequately controlled (defined as SBP $<140 \mathrm{~mm}$ $\mathrm{Hg}$ and $\mathrm{DBP}<90 \mathrm{~mm} \mathrm{Hg})$. Women were better controlled than men $(41.4 \% v 28.5 \%$ with normal blood pressure, respectively; $p$ value $=0.002$ ). The most common treatment $(45 \%$ of respondents treated for hypertension) was $\beta$ blockers.

Tables 2 and 3 examine the frequency of other cardiovascular risk factors in normotensive and hypertensive participants. Those with hypertension, whether male or female, had higher BMIs, waist girth, hip girth and waist/hip ratio in both genders. In hypertensive women, mean plasma total cholesterol, triglycerides and LDL-cholesterol were higher than in normotensive individuals ( $\mathrm{p}$ value $<0.05$ ).

As these risk factors vary with age table 4 shows the odds of having hypertension after adjusting for age according to exposure to a range of factors. As expected, hypertension was significantly positively related to family history of hypertension. Men and women who reported a family history were, respectively, $66 \%$ and $88 \%$ more likely to be hypertensive than their counterparts with no family history. The likelihood of being hypertensive also increased, in both sexes, with excess body weight ( $\mathrm{p}$ value for trend=0.01; fig 3 ). The likelihood of being hypertensive was higher in those with increased triglyceride levels, was significant only in men. Hypertension was not significantly associated with glucose intolerance, HDL or LDL cholesterol levels (tables 3 and 4), or with education, income, physical activity, or smoking status (results not shown).

After adjusting for factors found to be significant (age, family history, weight, and triglycerides), men were $63 \%$ more likely than women to be hypertensive (OR=1.63; $99 \% \mathrm{CI}: 1.13 \%$ to 2.36). This difference persisted even after sociodemographic (income, education) and lifestyle factors (smoking, sedentary physical activity level during leisure time, frequent alcohol consumption) were adjusted for (results not shown).

The data made it possible to test a hypothesis generated in an earlier study from Bahrain, ${ }^{24}$ which had shown an inverse association between education and blood pressure. This was taken as evidence in favour of a link between adverse circumstances in childhood and adult hypertension. In this study, however, there was no such association after adjusting for gender, age, and body mass index. The odds ratio for being hypertensive (with primary education as the index category) was 1.19 (95\% CI 0.71 to 1.98 ) for secondary and 0.98 (95\% CI 0.59 to 1.62 ) for higher education.

Given the tendency of risk factors to cluster, the simultaneous occurrence of four major CVD risk factors (hypertension, obesity, smoking, and hypertriglyceridaemia) is described in

Table 2 Mean (SD) values of cardiovascular risk factors by blood pressure in men

\begin{tabular}{|c|c|c|c|c|c|c|}
\hline & Normotensive & $\begin{array}{l}\text { Newly diagnosed } \\
\text { hypertensive }\end{array}$ & $\begin{array}{l}\text { Known untreated } \\
\text { hypertensive }\end{array}$ & $\begin{array}{l}\text { Known treated } \\
\text { hypertensive }\end{array}$ & Total hypertensive & p Value* \\
\hline Number of subjects & $n=339$ & $n=91$ & $n=20$ & $\mathrm{n}=85$ & $n=196$ & \\
\hline Mean age (y) & $51.8(13.4)$ & $54.5(12.0)$ & $55.5(12.8)$ & $61.4(8.9)$ & $57.6(11.3)$ & $<0.0001$ \\
\hline Mean height $(\mathrm{cm})$ & $171.7(6.8)$ & $171.6(7.3)$ & $172.9(5.6)$ & $170.5(5.9)$ & $171.3(6.6)$ & 0.50 \\
\hline Mean BMI $\left(\mathrm{kg} / \mathrm{m}^{2}\right)$ & $27.3(3.5)$ & $28.4(3.5)$ & $29.0(3.1)$ & $28.3(3.8)$ & $28.4(3.6)$ & 0.001 \\
\hline Mean waist $(\mathrm{cm})$ & 91.5 (11.2) & $95.5(10.8)$ & $99.3(9.2)$ & $96.4(9.9)$ & $96.3(10.3)$ & $<0.0001$ \\
\hline Mean hip (cm) & $102.3(8.6)$ & $103.7(8.2)$ & $109.0(11.0)$ & $105.2(10.0)$ & $104.9(9.4)$ & 0.001 \\
\hline Mean waist/hip index & $0.89(0.08)$ & $0.92(0.07)$ & $0.91(0.07)$ & $0.92(0.07)$ & $0.92(0.07)$ & 0.001 \\
\hline $\begin{array}{l}\text { Mean total cholesterol } \\
(\mathrm{mmol} / \mathrm{l})\end{array}$ & $5.3(1.1)$ & $5.4(1.1)$ & $5.3(1.4)$ & $5.3(1.2)$ & $5.4(1.2)$ & 0.70 \\
\hline Mean triglycerides $\dagger(\mathrm{mmol} / \mathrm{l})$ & 4.71 (4.66 to 4.76$)$ & 4.84 (4.73 to 4.95$)$ & 4.78 (4.56 to 5.00$)$ & 4.77 (4.66 to 4.87 ) & 4.81 (4.74 to 4.88 ) & 0.04 \\
\hline Mean HDL $(\mathrm{mmol} / \mathrm{l}) \ddagger$ & 3.68 (3.67 to 3.69$)$ & 3.67 (3.65 to 3.69$)$ & 3.66 (3.65 to 3.67$)$ & 3.67 (3.65 to 3.69$)$ & 3.67 (3.65 to 3.69$)$ & 0.13 \\
\hline Mean LDL (mmol/l) $\S$ & 4.91 (4.88 to 4.94$)$ & 4.93 (4.86 to 4.99 ) & 4.94 (4.80 to 5.08 ) & 4.94 (4.87 to 5.01$)$ & 4.93 (4.89 to 4.97$)$ & 0.38 \\
\hline
\end{tabular}

${ }^{*} p$ Value for difference between hypertensive and normotensive. †Geometric mean ( $99 \%$ confidence intervals), means for triglycerides are calculated with triglycerides set to missing for all those who did not fast $(n=17 ; 3.2 \%)$. $\ddagger$ Geometric mean $(99 \%$ confidence intervals), means for HDL-cholesterol are calculated with plasma HDL-C set to missing for all those who did not fast ( $n=17 ; 3.2 \%)$. §Geometric mean $(99 \%$ confidence intervals), means for LDL-cholesterol are calculated with plasma LDL-C set to missing for all those who did not fast $(n=17 ; 3.2 \%)$; 
Table 3 Mean (SD) values of cardiovascular risk factors by blood pressure in women

\begin{tabular}{|c|c|c|c|c|c|c|}
\hline & Nonrmotensive & $\begin{array}{l}\text { Newly diagnosed } \\
\text { hypertensive }\end{array}$ & $\begin{array}{l}\text { Known untreated } \\
\text { hypertensive }\end{array}$ & $\begin{array}{l}\text { Known treated } \\
\text { hypertensive }\end{array}$ & Total hypertensive & $p$ Value* \\
\hline Number of subjects & $n=425$ & $n=56$ & $n=11$ & $n=93$ & $n=160$ & \\
\hline Mean age $(y)$ & 50.2 (11.9) & $53.3(11.0)$ & $50.2(7.9)$ & $59.2(9.6)$ & $56.5(10.5)$ & $<0.0001$ \\
\hline Mean height $(\mathrm{cm})$ & $160.2(6.0)$ & $160.6(6.2)$ & $161.2(5.6)$ & $159.8(6.9)$ & $160.2(6.6)$ & 0.97 \\
\hline Mean BMI $\left(\mathrm{kg} / \mathrm{m}^{2}\right)$ & $28.1(4.5)$ & $29.3(4.9)$ & $30.1(3.8)$ & $30.1(4.4)$ & $29.8(4.5)$ & $<0.0001$ \\
\hline Mean waist $(\mathrm{cm})$ & 83.7 (10.9) & $88.5(10.6)$ & $89.6(9.3)$ & 91.7 (10.7) & $90.5(10.6)$ & $<0.0001$ \\
\hline Mean hip (cm) & $103.6(10.4)$ & $105.9(8.7)$ & $108.4(11.2)$ & $109.0(11.4)$ & $107.9(10.5)$ & $<0.0001$ \\
\hline Mean waist/hip index & $0.81(0.08)$ & $0.84(0.08)$ & $0.83(0.04)$ & $0.84(0.08)$ & $0.84(0.8)$ & $<0.0001$ \\
\hline Mean total cholesterol $(\mathrm{mmol} / \mathrm{l})$ & $5.4(1.3)$ & $5.6(1.3)$ & $6.6(1.9)$ & $5.8(1.1)$ & $5.8(1.3)$ & 0.004 \\
\hline Geometric mean triglycerides $\uparrow(\mathrm{mmol} / \mathrm{l})$ & 4.64 (4.59 to 4.68$)$ & 4.76 (4.60 to 4.92$)$ & 5.03 (4.68 to 5.38$)$ & 4.75 (4.66 to 4.83$)$ & 4.77 (4.69 to 4.85$)$ & 0.003 \\
\hline Geometric mean HDL (mmol/l) & $3.69(3.67$ to 3.70$)$ & 3.66 (3.63 to 3.69$)$ & 3.66 (3.49 to 3.83 ) & 3.66 (3.64 to 3.68 ) & 3.66 (3.64 to 3.68$)$ & 0.049 \\
\hline Geometric mean LDL§ (mmol/l) & 4.97 (4.94 to 4.97$)$ & 5.02 (4.95 to 5.09$)$ & 5.14 (4.99 to 5.29$)$ & 5.04 (4.99 to 5.09 ) & 5.04 (5.00 to 5.08 ) & 0.008 \\
\hline
\end{tabular}

* $p$ Value for difference between hypertensives and normotensives. †Geometric mean $(99 \%$ confidence intervals), means for triglycerides are calculated with triglycerides set to missing for all those who did not fast ( $n=17 ; 3.2 \%)$. ‡Geometric mean ( $99 \%$ confidence intervals), means for HDL-cholesterol are calculated with plasma HDL-C set to missing for all those who did not fast ( $n=17 ; 3.2 \%)$. §Geometric mean ( $99 \%$ confidence intervals), means for LDL-cholesterol are calculated with plasma LDL-C set to missing for all those who did not fast $(n=17 ; 3.2 \%)$.

Table 4 Odds ratios of having hypertension according to presence of other cardiovascular risk factors, adjusting for age

\begin{tabular}{|c|c|c|c|c|c|c|}
\hline & \multicolumn{3}{|l|}{ Men } & \multicolumn{3}{|l|}{ Women } \\
\hline & Odds ratio & $99 \% \mathrm{Cl}$ & $\mathrm{p}$ Value & Odds ratio & $99 \% \mathrm{Cl}$ & $\mathrm{p}$ Value \\
\hline $\begin{array}{l}\text { Family history of hypertension } \\
\text { Relative weight categories* }\end{array}$ & 1.66 & 1.01 to 2.73 & 0.009 & 1.88 & 1.11 to 3.19 & 0.002 \\
\hline Overweight & 1.82 & 0.94 to 3.52 & 0.02 & 1.82 & 0.85 to 3.88 & 0.04 \\
\hline Obese & 2.37 & 1.11 to 5.05 & 0.003 & 2.42 & 1.13 to 5.18 & 0.003 \\
\hline Central obesity & 1.11 & 0.65 to 1.91 & 0.62 & 1.45 & 0.86 to 2.44 & 0.065 \\
\hline Total cholesterol $>6.5 \mathrm{mmol} / \mathrm{I}$ & 1.35 & 0.64 to 2.86 & 0.30 & 0.79 & 0.42 to 1.46 & 0.32 \\
\hline HDL cholesterol & 1.13 & 0.69 to 1.85 & 0.53 & 0.88 & 0.15 to 5.29 & 0.86 \\
\hline Triglycerides $>1.69 \mathrm{mmol} / \mathrm{l}$ & 1.65 & 1.00 to 2.71 & 0.01 & 1.25 & 0.74 to 2.12 & 0.27 \\
\hline LDL cholesterol >3.38 mmol// & 1.25 & 0.77 to 2.04 & 0.24 & 1.15 & 0.66 to 2.02 & 0.51 \\
\hline \multicolumn{7}{|l|}{ Glucose tolerance $\dagger$} \\
\hline Impaired glucose tolerance & 1.51 & 0.35 to 6.59 & 0.47 & 1.41 & 0.41 to 4.82 & 0.47 \\
\hline Diabetes & 1.44 & 0.58 to 3.56 & 0.30 & 0.88 & 0.31 to 2.49 & 0.75 \\
\hline
\end{tabular}

*Normal/underweight as baseline category. †Normal glucose tolerance as baseline category. łLow high density lipoprotein (HDL) cholesterol: < 1.04 $\mathrm{mmol} / \mathrm{l}$ in men and $<1.29 \mathrm{mmol} / \mathrm{l}$ in women. Significant values in bold.

table 5. Age standardised proportions are given separately for men and wowmen. Men were more likely to be hypertensive, smoke and have high triglycerides levels while women were more likely to be obese. The combination of hypertension with obesity was more likely in women, while men were more likely to have the combination of hypertension with smoking and hypertriglyceridaemia. Men were more likely than women to have clustering of hypertension with two other risk factors (obesity and/or smoking or hypertriglyceridaemia). Finally, the simultaneous occurrence of all four risk factors was rare but much more likely among men than women.

The percentages in each group meeting the criteria for the metabolic syndrome are shown in figures 4 and 5, for comparison, figures from the American National Health and

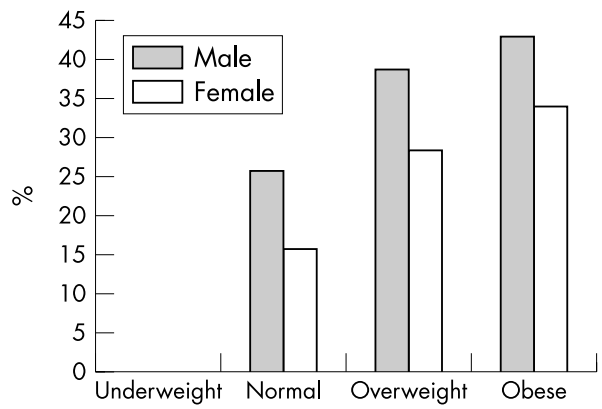

Figure 3 Distribution of hypertension by body weight categories in men and women.
Nutrition Survey, which is one of the few other sources of population prevalence of this syndrome. ${ }^{25}$

\section{DISCUSSION}

This study provides important new evidence on the prevalence of hypertension and other cardiovascular risk factors in Albania and creates a baseline against which future changes can be assessed. It showed that more than one in three men and one in four women aged 25 years and over in Tirana City suffer

Table 5 Frequency and clustering of CVD risk factors (hypertension, obesity, smoking, and hypertriglyceridaemia) by sex

\begin{tabular}{lll}
\hline Risk factors & $\begin{array}{l}\text { Male (age } \\
\text { adjusted)* } \%\end{array}$ & $\begin{array}{l}\text { Female (age } \\
\text { adjusted)*\% }\end{array}$ \\
\hline Hypertension (HT) & $36.6(30.2)$ & $27.4(22.7)$ \\
Obesity (O) & $22.8(22.0)$ & $35.6(30.9)$ \\
Smoking (S) & $37.6(44.4)$ & $19.3(21.6)$ \\
Hypertriglycerides (HTG) & $23.6(23.9)$ & $19.1(15.4)$ \\
HT + O & $9.7(8.8)$ & $12.0(10.4)$ \\
HT + S & $12.5(11.6)$ & $4.6(4.3)$ \\
HT + HTG & $9.2(7.9)$ & $6.3(5.2)$ \\
HT + O + S & $3.9(4.3)$ & $1.9(2.2)$ \\
HT + O + HTG & $3.6(3.2)$ & $2.9(2.7)$ \\
HT + S + HTG & $4.7(4.2)$ & $1.2(1.4)$ \\
HT + O + S + HTG & $1.7(1.5)$ & $0.3(0.7)$ \\
\hline
\end{tabular}

*Prevalence rates were age adjusted by the direct method using the age distribution of the Tirana population (INSTAT 1998 data). 


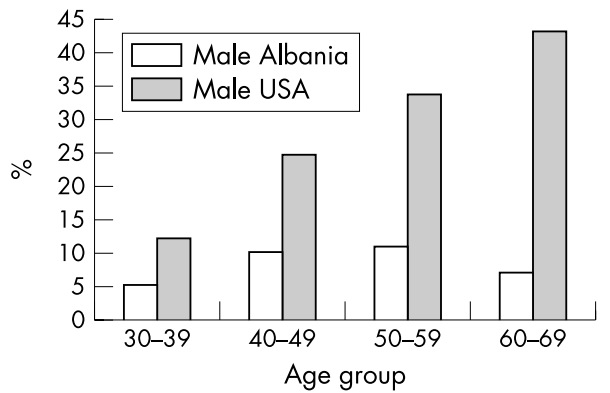

Figure 4 Prevalence of the metabolic syndrome in men.

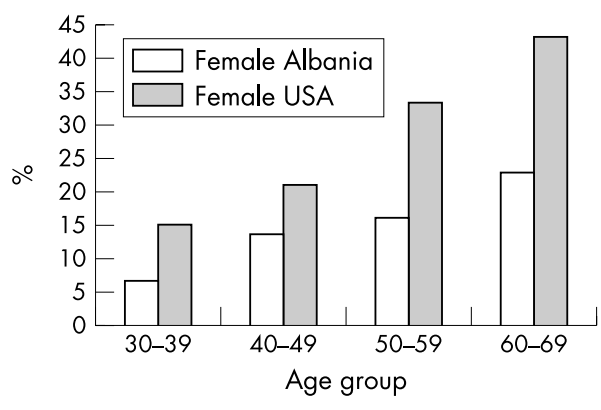

Figure 5 Prevalence of the metabolic syndrome in women.

from hypertension and that about one in ten people are both hypertensive and obese. These figures are surprising in a society that has relatively recently moved from a very traditional lifestyle. Before the results are discussed further, the strength and limitations of the study must be considered.

A major strength of the survey is its relatively high response rate $(72.7 \%)$, comparable to the rates achieved in recent surveys conducted in other countries in transition. ${ }^{26-28}$ Despite this, the final sample was not entirely representative of the general population in terms of age as it included a lower than expected proportion of younger people. As this might have led to an overestimation of the true prevalence of hypertension, overall prevalence rates were age standardised to the Tirana City population (1998 INSTAT data). Another limitation of the study is the fact while some respondents were from the same households, information on variance inflation due to clustering was not available. As a result, it is possible that the true standard errors of the estimates were underestimated and that the risk of type I error was increased. In an attempt to counterbalance these effects, we have increased the significance level to $p=0.01$ and calculated $99 \%$ confidence intervals. However, it is important to note that most significant findings in this study remained significant at the even smaller significance level of 0.001 .

As noted above, Albania has been extremely isolated during much of the 20th century and, to our knowledge this study provides the only data on the prevalence of hypertension and clustering of CVD risk factors in the largest urbanised part of Albania (including nearly $20 \%$ of the Albanian population). However, the results cannot be generalised to the whole country, as it is probable that diet, physical activity levels, and consequently the prevalence of hypertension would differ in rural areas. Thus, our estimates may be higher than what would be found in a nationally representative survey. A better understanding of the impact of changing lifestyles in both urban and rural areas is thus urgently needed in this society in transition.

Elsewhere we have reported how this population has experienced a rapid increase in the prevalence of diabetes since the transition. ${ }^{10}$ Unfortunately, as already noted, we do not have historical data with which to compare our findings. However, data are available from the Seven Country Study, which had study sites in Greece and Italy. Data on a range of risk factors were recorded at entry in 1960-1961 and repeated 10 years later. The data in the present survey indicate that the urban population of Albania exhibit a risk profile that is consistent with what existed in Greece and Italy in the early 1960s (table 6). ${ }^{29}$

However, a different pattern is seen when the percentage of people classified as hypertensive is considered, rather than the mean blood pressure. In this case, the percentage that is hypertensive is identical among men (30.2\%) although rather lower $(22.7 \%$ versus $27.1 \%)$ among women in comparison with contemporary Greeks. ${ }^{30}$ However, the prevalence of hypertension is still considerably lower than in other, albeit rather more industrialised former communist countries, such as Hungary $(37.2 \%)^{31}$ or in Russia $(36 \%) .^{32}$

As expected, this study showed clear gender differences in the prevalence of hypertension, with men being more likely to be hypertensive than women, even after adjusting for various sociodemographic and lifestyle factors, family history of hypertension, and excess body weight. Surveys conducted in other countries in transition ${ }^{33-35}$ found similar gender differences in the prevalence of hypertension.

In our study population, we observed that more than half the respondents treated for hypertension were adequately controlled. This is more than what was expected based on findings from surveys conducted in Hungary, ${ }^{26}$ Belgium, ${ }^{36}$ or China $^{29}$ that reported much higher unsatisfactory levels of blood pressure control $(20 \%-30 \%)$ in respondents receiving treatment for hypertension.

The lack of an association between education and hypertension was not entirely surprising. The massive scale of transition in Albania means that earlier social hierarchies have been almost entirely disrupted.

In recent years it has been proposed that hypertension is part of a cluster of metabolic risk factors (syndrome $\mathrm{X}$ ) involving hyperlipidaemia (raised plasma triglycerides and low HDL cholesterol levels) and hyperglycaemia, with hyperinsulinaemia as the common link..$^{37-39}$ In this survey, only excess weight, family history of hypertension and, among men, increased triglycerides, were associated with hypertension. The association with a positive family history of hypertension and excess weight has been reported in many studies. ${ }^{40-42}$

To place Albania in a comparative perspective in terms of overall risk factors, given that the effects of cardiovascular risk factors tend to be synergic, ${ }^{43}$ other studies that had looked at the combination of factors were identified. The prevalence of a combination of risk factors (obesity, hypertension, smoking)

\begin{tabular}{|c|c|c|c|c|c|}
\hline & \multirow{2}{*}{2000} & \multicolumn{2}{|c|}{$1960 / 61$} & \multicolumn{2}{|c|}{$1970 / 71$} \\
\hline & & Italy & Greece & Italy & Greece \\
\hline $\begin{array}{l}\text { Body mass index } \\
\text { Systolic blood pressure (mm Hg) } \\
\text { Cholesterol (mmol/l) }\end{array}$ & $\begin{array}{l}28.6 \\
133.7 \\
5.4\end{array}$ & $\begin{array}{l}25.2 \\
143.3 \\
5.2\end{array}$ & $\begin{array}{l}23.1 \\
135.9 \\
5.3\end{array}$ & $\begin{array}{l}26.1 \\
152.6 \\
5.7\end{array}$ & $\begin{array}{l}24.3 \\
141.4 \\
5.9\end{array}$ \\
\hline
\end{tabular}


was considerably lower than in Hungary, ${ }^{31}$ in what was the most comparable study from a society in transition, although the Hungarian study did not report lipid levels. However, what was most striking was that the combination of risk factors that make up the metabolic syndrome, which can be considered a proxy indicator of overall cardiovascular risk, was very much lower than in the American population.

In conclusion, these findings provide important new evidence on the prevalence of hypertension and its association with other cardiovascular risk factors in Albania. Albania is changing rapidly. The prevalence of hypertension is, as in other societies in transition, a cause for concern but the levels of other cardiovascular risk factors remain somewhat lower than in other industrialised and transition countries, suggesting that Albania has so far not entirely lost its relative advantage.

These findings have important implications for both health care and health promotion. Although there was a relatively low frequency of undiagnosed hypertension, a substantial number of those affected had not achieved adequate control. There is now compelling evidence from several countries in this region that have experienced a turbulent transition that the management of longstanding diseases often suffers. ${ }^{44}$ It will be important that future Albanian health care reforms, which in other post-transition countries have tended to focus on acute care, do not make the management of longstanding disorders more difficult. The risks are particularly great because those suffering from chronic diseases are often old and with limited resources. It is almost inevitable that the risk factor profile in Albania will worsen in the coming years. Given the many profound challenges facing Albania the development and implementation of an effective health strategy will inevitably be very difficult. However, it is essential not to allow the magnitude of the task to prevent any action. It may not be easy to influence the changing pattern of nutrition but other risk factors, such as smoking, whose actions are synergistic with those discussed here, can be tackled now.

\section{ACKNOWLEDGEMENT}

We would like to thank all the staff of Diabetic Centre "Neo-Style" in Tirana for their collaboration and support.

\section{Authors' affiliations}

L Shapo, J Pomerleau, M McKee, European Centre on Health of Societies in Transition, London School of Hygiene and Tropical Medicine, London, UK

Funding: this study was funded by the Wellcome Trust (project grant no 061573). However, the Wellcome Trust cannot accept any responsibility for any information provided or views expressed.

Conflicts of interest: none declared.

\section{REFERENCES}

1 Kannel WB, Castelli WP, McNamara PM, et al. Role of blood pressure in the development of congestive heart failure: the Framingham Heart Study. N Engl J Med 1972;287:781-7.

2 Savage PJ. Treatment of diabetes mellitus to reduce its chronic cardiovascular complications. Curr Opin Cardiol 1998;13:131-8.

3 Manson JE, Colditz GA, Stamfer M, et al. A prospective study of obesity and risk of CHD in women. N Engl J Med 1990;332:882-9.

4 Hierman I, Velve Byre K, Holme I, et al. Effect of diet and smoking intervention on the incidence of coronary heart disease. Lancet 1981 ; ii:1303-10.

5 World Health Report. Reducing risks, promoting healthy life. 2002 http://www.who.int/whr/en

6 Shapo L, Gilmore ABC, Cooker R, et al. Prevalence and determinants of smoking in Albania: results from a population-based survey in Tirana City. Public Health (in press).

7 Gjonca A. Communism, health and lifestyle. The paradox of mortality transition in Albania, 1950-1990. Westport, CT: Greenwood Press, 2001.

8 Gjonca A, Bobak M. Albanian paradox, another example of protective effect of Mediterranean lifestyle? Lancet 1994;350:1815-17.

9 Shapo L, Pomerleau J, McKee M. Physical inactivity in a country in transition: a population-based survey in Tirana City, Albania. Scand J Public Health (in press).
10 Shapo L, McKee M, Cooker R, et al. Type 2 diabetes in Albania: a rapid increase in a county in transition. Diabet Med (in press).

11 Henderson RH, Sundaresan T. Cluster sampling to assess immunization coverage: a review of experience with a simplified sampling method. Bull WHO 1982;60:253-60.

12 Reference withdrawn.

13 Pomerleau J, McKee M, Robertson A, et al. Physical inactivity in the Baltic countries. Prev Med 2000;31:665-72.

14 World Health Organisation. WHO Expert Committee on diabetes mellitus. Second Report (Tech Report Series no 626). Geneva: WHO, 1980.

15 World Health Organisation. Obesity. Preventing and managing the global epidemic. Geneva: WHO, 1997.

16 British Heart Foundation Health Promotion Research Group. Coronary heart diseases statistics. Oxford: British Heart Foundation Promotion Research Group, 2002.

17 Ataman SL, Cooper RS, Rotimi CN, et al. Standardization of blood pressure measurements in an international comparative study. J Clin Epidemiol 1996:49:869-77.

18 Cooper RS, Rotimi CN, Ataman SL, et al. Prevalence of hypertension in seven populations of African origin. Am J Public Health 1997;87:160-9

19 WHO. Part 1: Diagnosis and classification of diabetes mellitus, Report of WHO Consultation. Geneva: WHO, 1999

20 The Expert Committee on the Diagnosis and Classification of Diabetes mellitus. Report. Diabetes Care 1997;20:1 183-97.

21 Rao JNK, Scott AJ. A simple method for the analysis of clustered binary data. Biometrics 1992;48:577-85

22 Trevisan M, Liu J, Bahsas FB, et al. Syndrome X and mortality: population-based study. Risk Factor and Life Expectancy Research Group. Am J Epidemiol 1998;148:958-66

23 Executive Summary of The Third Report of The National Cholesterol Education Program (NCEP) Expert Panel on Detection, Evaluation, And Treatment of High Blood Cholesterol In Adults (Adult Treatment Panel III). JAMA 2001;285:2486-97.

24 Al-Mahroos F, Al-Roomi K, McKeigue PM. Relation of high blood pressure to glucose intolerance, plasma lipids and educational status in an Arabian Gulf population. Int J Epidemiol 2000;29:71-6.

25 Ford ES, Giles WH, Dietz WH. Prevalence of the metabolic syndrome among US adults: findings from the third National Health and Nutrition Examination Survey. JAMA 2002;287:356-9.

26 Pudule I, Grinberga D, Kadziauskiene K, et al. Patterns of smoking in the Baltic Republics. J Epidemiol Community Health 1999;53:277-83.

27 McKee M, Pomerleau J, Robertson A, et al. Alcohol consumption in the Baltic Republics. J Epidemiol Community Health 2000;54:361-6.

28 Pomerleau J, McKee M, Robertson A, et al. Physical inactivity in the Baltic countries. Prev Med 2000;31:665-72.

29 Dontas AS, Menotti A Aravanis S, et al. Comparative total mortality in 25 years in Italian and Greek middle aged rural men. J Epidemiol Community Health 1998;52:638-44.

30 Stergiou GS. Prevalence, awareness treatment and control of hypertension in Greece: the DIDIMA study. [Abstract]. J Hypertens 1999;17 (suppl 3):S286.

31 Jenei Z, Pall D, Katona E, et al. The epidemiology of hypertension and its associated risk factors in the city of Debrecen, Hungary. Public Health 2002; 1 16: 138-44

32 Britov A. Epidemiology of hypertension in Moscow suburban area: health service personal insight. [Abstract]. J Hypertens 1999;17:(suppl 3): 517.

33 Grim CE, Grim CM, Petersen JR, et al. Prevalence of cardiovascular risk factors in the Republic of Georgia. J Hum Hypertens 1999;13:243-7.

34 Wu DM, Pai L, Chu NF, et al. Prevalence and clustering of cardiovascular risk factors among healthy adults in a Chinese population: the M Health Screening Centre Study in Taiwan. Int J Obes 2001;25:1189-95.

35 Edwards R, Unwin N, Mugusi F, et al. Hypertension prevalence and care in an urban and rural area of Tanzania. J Hypertens 2000; 18: 145-52

36 Duprez D, Helshoecht PV, Eynde WV, et al. Prevalence of hypertension in the adult population of Belgium: report of a worksite study, Attention Hypertension. J Hum Hypertens 2002;16:47-52.

37 Wannamethee SG, Shaper AG, Durrington PN, et al. Hypertension, serum insulin, obesity and the metabolic syndrome. J Hum Hypertens 1998; 12:735-41

38 Reaven GM. Role of insulin resistance in human disease. Diabetes 1988;37:1595-607.

39 McKeigue PM, Shah B, Marmot MG. Relation of central obesity and insulin resistance with high diabetes prevalence and cardiovascular risk in South Asians. Lancet 1991;337:382-6

40 Reyes-Gibby CC, Aday LA. Prevalence of and risk factors for hypertension in a rural area of the Philipines. J Community Health 2000;25:389-99

41 Lamon-Fava S, Wilson PWF, Schaefer EJ. Impact of body mass index on coronary heart disease risk factors in men and women. The Framingham Offspring Study. Arterioscler Thromb Vasc Bio 1996; 16:1509-15

42 Dyer AR, Elliott P. INTERSALT Co-operative Research Group. The INTERSALT Study: relations of body mass index to blood pressure. J Hum Hypertens 1989;3:299-308

43 Jee SH, Appel L, Suh I, et al. Prevalence of cardiovascular risk factors in South Korean adults: results from the Korea Medical insurance Corporation (KMIC) Study. Ann Epidemiol 1998;8:14-21.

44 Telishevska $M$, Chenet $\mathrm{L}$, McKee $M$. Towards an understanding of the high death rate among young people with diabetes in Ukraine. Diabet Med 2001;18:3-9. 